\title{
Mechanical circulatory support systems: evolution, the systems and outlook
}

\author{
Roland Hetzer ${ }^{1}$, Mariano Francisco del Maria Javier ${ }^{1}$, Michael Dandel ${ }^{1}$, Matthias Loebe ${ }^{2}$, \\ Eva Maria Javier Delmo ${ }^{3}$
}

${ }^{1}$ Department of Cardiothoracic and Vascular Surgery, Cardio Centrum Berlin, Berlin, Germany; ${ }^{2}$ Thoracic Transplant and Mechanical Support, Miami Transplant Institute, Memorial Jackson Health System, University of Miami, Miami, FL, USA; ${ }^{3}$ Charité Research Organization, Universitätsmedizin Berlin-Charité, Berlin, Germany

Contributions: (I) Conception and design: All authors; (II) Administrative support: R Hetzer; (III) Provision of study materials or patients: All authors; (IV) Collection and assembly of data: All authors; (V) Data analysis and interpretation: All authors; (VI) Manuscript writing: All authors; (VII) Final approval of manuscript: All authors.

Correspondence to: Eva Maria Javier Delmo, MD, MSc, PhD. Charité Research Organization, Universitätsmedizin Berlin-Charité, Virchowweg 10, 10117 Berlin, Germany. Email: eva.javierdelmo@gmail.com.

\begin{abstract}
The joint efforts in the fields of surgery, medicine and biomedical engineering, sponsored by both the government and the industry, have led to the development of mechanical support devices that can provide reliable circulatory support, which can temporarily support a patient's circulation until either the heart recovers or until a new heart can be transplanted or permanently replace a failed heart. Their development has been driven by the shortage of donor organs. Various systems have eventually evolved for short or long-term support of patients suffering from cardiogenic and/or advanced heart failure (HF). Over time, several have been withdrawn from the market due to high rate of thromboembolism and pumprelated complications, but many others remained with modern principles of circulatory support proved to be durable and reliable. Hopefully, the ever-evolving technology will yield several devices aimed at their miniaturization, with an energy supply without risk of infection, a system which is simple to implant and to exchange, minimalization of thrombus formation by optimal interior pump design, new antithrombotic medications and a system with demand-based pump activity. It is important to remember that such devices are only implanted to keep a patient alive or in an immediate life-threatening stage. In such circumstances, attribution of aforementioned difficulties to pump limitations or to advanced disease states remains difficult. In the coming years, ventricular assist devices (VADs) could be the most common surgical preference for treating severe HF.
\end{abstract}

Keywords: Continuous flow ventricular assist device (continuous flow VAD); extracorporeal ventricular assist device (extracorporeal VAD); pulsatile pumps; total artificial heart (TAH); thromboembolism

Submitted Feb 25, 2020. Accepted for publication Apr 21, 2020.

doi: $10.21037 / \mathrm{cdt}-20-283$

View this article at: http://dx.doi.org/10.21037/cdt-20-283

\section{Introduction}

The idea of mechanical circulatory support (MCS) has existed for more than 200 years. However, it has only been within the past 5 decades that joint efforts in the fields of surgery, medicine and biomedical engineering, funded by the government and industries, have led to the development of mechanical support devices that could provide reliable circulatory support, temporarily supporting a patient's circulation either until recovery, transplantation or as a means to permanently replace a failed heart. The development of MCS devices has been driven by the shortage of donor organs. The lack of organ availability is overcome by initially keeping the patient alive through a 
mechanical circulatory support system (MCSS) in the face of threatening heart failure (HF) until the patient can be heart transplanted or by implanting the system permanently instead of transplantation. In the coming years, ventricular assist devices (VADs) could become the most common surgical choice for treating severe HF, possibly exceeding the frequency of orthotopic heart transplantation (OHT).

\section{History of MCS}

Several milestones are worth mentioning in the evolution of MCS with VAD and with a total artificial heart (TAH). In 1937, Vladimir Demikhov (1) replaced a dog's heart with two diaphragm pumps. A year later [1938], Carrel and Lindbergh (2) attempted to design a functional cardiac support system. In 1951, Dennis $(3,4)$ performed the first open heart surgery on a human using left heart bypass. Then the modern era of cardiac surgery began in 1953 when Miller (5) first used a heart-lung machine (HLM) during the successful closure of an atrial septal defect.

This led to the development of pumps and gas exchangers (oxygenators) with the ability to take over the heart/heartlung function for a limited period of time. Such HLMs are the basis of today's cardiac surgeries. The HLM was the first support system to stabilize a patient after a cardiotomy. In 1957, Akutsu and Kolff (6-9) carried out the first experimental implantation of an artificial heart in dogs. The animal survived for 90 minutes. In 1961, Moulopoulos (10) introduced the use of an intraoperative balloon pump as a temporary support. In 1962, Liotta from Baylor College in Houston, Texas, reported the first clinical use of an artificial ventricle in a patient with cardiogenic shock after aortic valve surgery (11). This primitive device connected the left atrium (LA) to the descending thoracic aorta consisting of a pneumatically operated, tubular positive displacement pump. After a postoperative standstill, the pump provided sufficient circulation for 4 days before the patient died of multiorgan failure. Based on these reports, the United States National Institute of Health established the Artificial Heart Program in 1964. Six companies were commissioned to investigate the technical feasibility of mechanical heart pumps, which should not only allow a bridge to recovery (BTR) from acute HF, but also permanent cardiac replacement. In 1965, DeBakey used the first pneumatic left VAD (LVAD), then known as the "left ventricular bypass pump", to support a patient until heart recovery 10 days after cardiac surgery (12).

After the first venture in 1969 by Cooley, who implanted the TAH developed by Liotta as a bridge to transplant (BTT) $(13,14)$, efforts continued worldwide on its development by several groups, such as Pierce (Hershey) $(15,16)$, Nosé (Houston) (17), Shumakov (Moscow) (18,19), Wolner and Navratil (Brno, Vienna) (20), Bücherl (Berlin) (21), Klinkmann (Rostock) (22), with various system configurations being tested. All of these partially monstrous pneumatic drive systems had high thromboembolic rates, hemolysis and other complications. The Pierce system was implanted in humans in 1978 (16) and then the Jarvik 7, also a pneumatically driven TAH, developed by Jarvik (23) and by DeVries (24) who implanted the device in Salt Lake City in 1982, where it worked well for 112 days in the famous patient Barney Clark until he died. This case attracted a worldwide attention, followed by a series of further implantations until the US government issued a moratorium on the continued use of the device due to high rates of thromboembolism and stroke in 1984.

The system was continuously utilized in large numbers (>100 cases) by Cabrol (25) in Paris as CardioWest and kept alive as the only approved TAH available. Currently, there is a new impetus for the TAH, through the CARMAT TAH, developed by Carpentier in France with the EADS company in 1993 (26).

Several TAH were implanted on patients by Bücherl in 1986 (27), successfully by Hetzer (28), Wolner (29) and Shumakov (30) in 1987.

Simultaneously, the establishment of other support systems continued, initially to stabilize the cardiac function after cardiac surgery, and later as a BTT, BTR and finally as a permanent alternative to transplantation.

These were initial VAD programs established by Norman in Houston (31), Bernhard in Boston (32), Pierce in Hershey (33) and Turina and Senning in Zurich (34), from 1975-1977. The Thoratec system with extracorporeal pumps marked the beginning of this company as a serious supporter of further VAD development, at the same time as the Berliner Bücherl program, pursued by Hetzer in collaboration with Berlin Heart in 1988 (35) which manufactured and marketed such extracorporeal pumps worldwide since then.

The only system for infants and small children to date evolved after Hetzer (36) implanted such a VAD as BTT in the first child worldwide. Since 1992, miniaturized VADs have been used in small children and distributed worldwide as $\mathrm{EXCOR}^{\circledR}$.

In the 1980s and 1990s, intracorporeal, electric pulsatile pumps were popularized but gradually disappeared with the 
introduction of the rotary pumps.

The first continuous-flow pump, an axial flow pump developed by DeBakey, was implanted in Berlin by Hetzer on November 13, 1998 (37). After having demonstrated that the human being tolerated all functions with a completely different, continuous blood flow, these pumps established itself over the other types of VADs, being small, quiet, energy-saving and overall with minor complication; hence, becoming the VAD standard.

With such axial flow systems based on the centrifugal principle, patients can now live 7-10 years (38). Within this duration, the VAD systems may be exchanged with the same or a different pump when necessary.

Recently, efforts have focused on avoiding complications through better anticoagulation, improving systems of energy transmission without skin injury and developing good monitoring concepts.

In this review, only the currently available ventricular support systems in terms of design and concept are described and discussed. Implantation techniques and outcome of each system is not undertaken; however, complications and outlook on these currently available systems are provided.

\section{Indications for the use of MCSSs}

In 2017 , the total number of cardiac procedures in Germany was 101,728 in 79 cardiac surgery centers: 47,673 coronary artery bypasses and 34,394 heart valve surgeries were performed. The total number of cardiac interventions using a HLM was 74,812 (39).

In patients who cannot be weaned off HLM, MCSS is used as first choice of treatment, as short-term temporary support for several days and weeks, until the heart recovers.

Since the previous classification of $\mathrm{HF}$ according to New York Heart Association (NYHA) does not address the different depths of cardiogenic shock, the US Interagency Registry for Mechanically Assisted Circulatory Support (INTERMACS) has created a more differentiated classification (40).

The levels are defined as follows: Level 1: critical cardiogenic shock (“crash and burn"); Level 2: progressive decline (circulatory deterioration); Level 3: stable but inotrope dependent; Level 4: resting symptoms; Level 5: exercise intolerance; Level 6: exertion limited; and Level 7: advanced NYHA III (40).

Levels 1-4 correspond to NYHA class 4 . We do not currently consider INTERMACS $5-7$ as an indication for
MCS. In line with previous experience, different system configurations are displayed at levels 1-4 in order to achieve successful circulatory stabilization.

Profound cardiogenic shock (Level 1) always requires a biventricular support system (BVAD) or a TAH. If left HF predominates (Level 2, 3, 4), the implantation of a left heart support system (LVAD) may be sufficient. In the event of impending right HF, the temporary additional right heart support is also indicated, and more recently the use of an implantable BVAD. In practice, a life-supporting extracorporeal temporary system, e.g., an extracorporeal membrane oxygenator (ECMO), is implanted to see if the organism can recover from the shock effects before a longterm support system is applied.

The risk of right HF after LVAD implantation can now be reliably predicted using echocardiographic criteria.

Possible contraindications are septic conditions, brain damage and advanced tumor diseases as well as the apparent impossibility of rehabilitation.

The ultimate life-saving option for a seriously ill patient is a heart transplant. The number of patients in the waiting list exceeds the number of available donor hearts. Patients on the waiting list for a heart transplant can slip into an immediately life-threatening HF. MCSS is then used as a last resort, in such cases. Various systems have been applied in Berlin under Hetzer's initiative since 1987, aimed at bridging the waiting time until a possible cardiac recovery, or, if a suitable donor organ is available, a subsequent transplantation. Such systems have also been implanted in patients who are either ineligible for OHT or who do not wish to have transplantation, for permanent support, called destination therapy.

Table 1 shows the spectrum of the VAD systems used successively in Berlin since 1988 with their number and their longest follow-up period (41). In a total of 1,920 patients (as of March 31, 2015), 17 different systems were used with maximum duration support of $>8$ years. This is considered the world's largest single-center experience with an accumulated time of more than 1,675 patient years.

\section{BTT}

Patients listed for OHT may develop uncontrollable HF if they wait longer and may need an MCSS to get a heart transplant. As such, patients who have received MCSS may be listed if they meet the heart transplant requirements.

Organ function impairment caused by HF before MCS implantation can be alleviated by circulatory 
Table 1 Long-term MCS implanted in Berlin (01.06.1988-31.05.2015) (41)

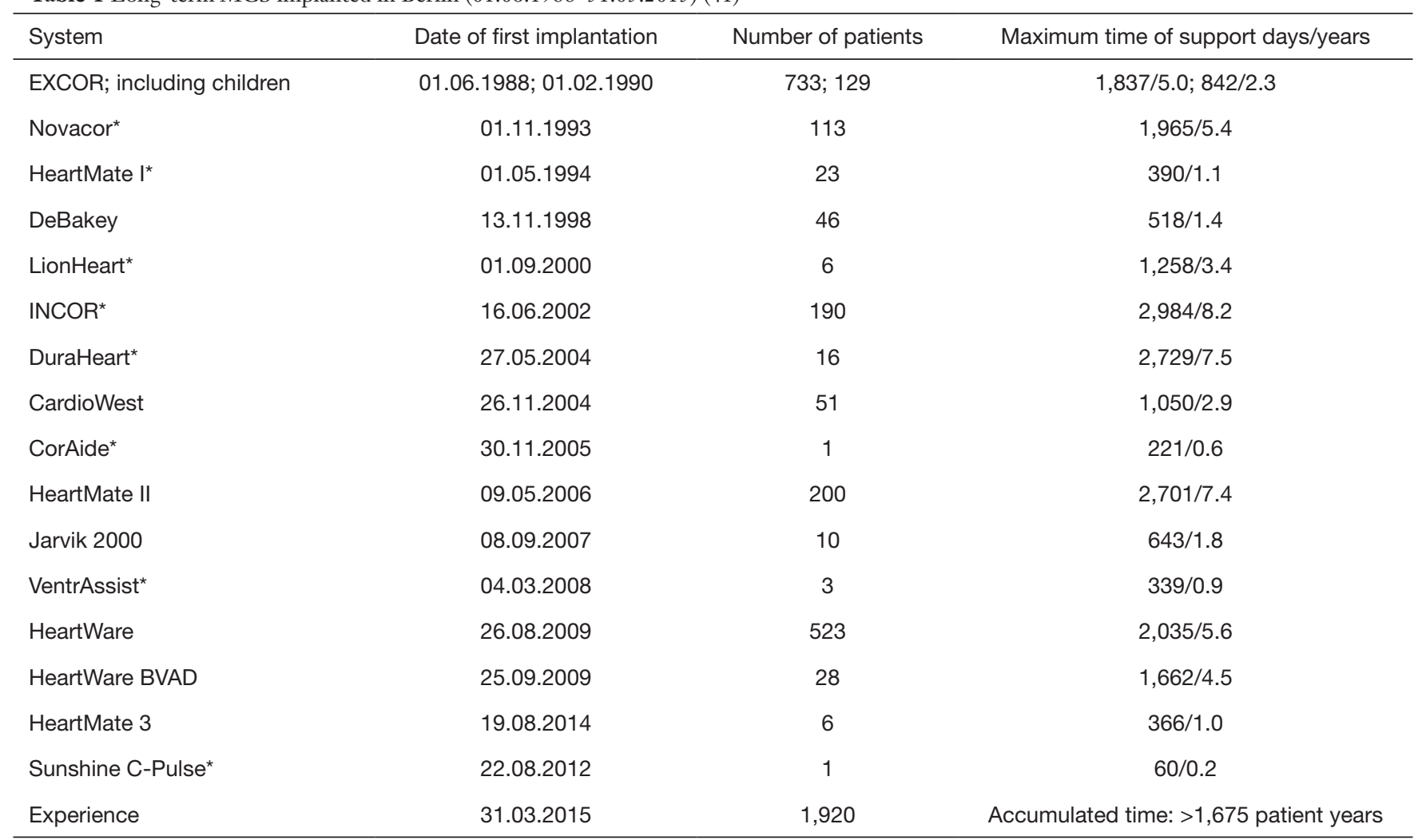

*, No longer available.

support. Congestion-related pulmonary, liver or kidney dysfunction, which are established contraindications along with significant gastrointestinal disease, any systemic infection or pulmonary infarction and severe elevation of pulmonary vascular resistance secondary to long-standing left ventricular failure or pulmonary emboli (42), could then be no longer a contraindication for an eventual heart transplant. The general condition of the patient is thus greatly improved in preparation for an elective heart transplantation.

\section{Bridge to myocardial recovery}

In certain etiologies of $\mathrm{HF}$, such as myocarditis or in dilated cardiomyopathy, a recovery of the myocardial function with temporary MCSS within days, weeks or months of support may be achieved and the system eventually be explanted.

$\mathrm{HF}$ after cardiosurgical interventions likewise can be stabilized and achieve effective cardiac recovery by unloading the LV.

\section{Bridge to decision (bridge to bridge)}

If the organ function, especially that of the brain, is impaired and uncertainty regarding the possibility of recovery exists, MCSS designed for short-term use, e.g., ECMO, stabilizes circulation, saves time for further diagnostics and provides an immediate clinical improvement. When the patient recovers, the short-term support can be switched to a longterm or to a permanent system.

\section{Permanent support or replacement of the pump function of the beart (destination therapy)}

The original goal was to develop systems for permanent use as a heart replacement. After many years of experience in temporary MCSS, some available systems can be used as destination therapy. Patients with known contraindications to OHT or who refuse to undergo the procedure can be provided with extracorporeal or implantable VADs or with an older TAH model to prolong their lives with a reasonable perspective. With extensive follow-up care and regular 
Table 2 Generations of the clinically used MCSS

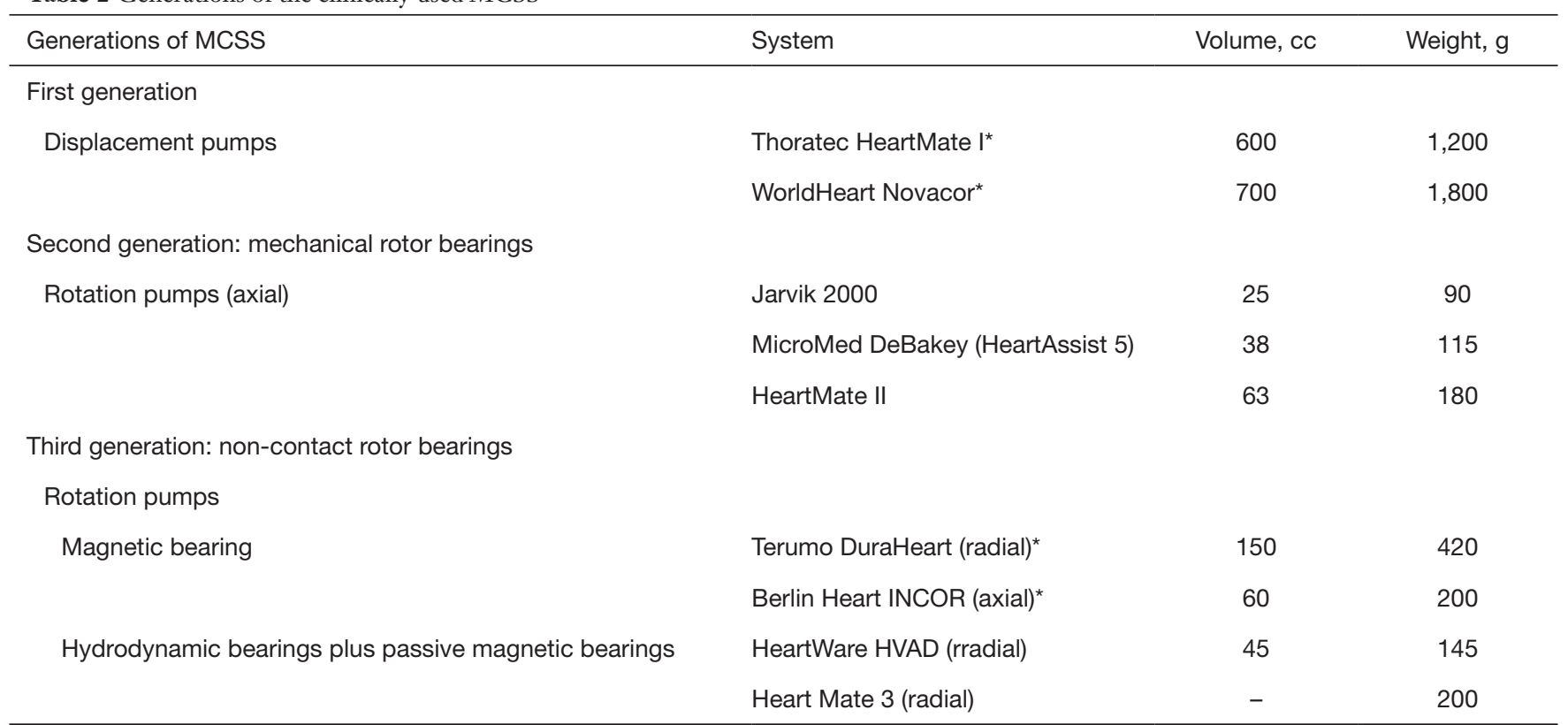

*, No longer available.

system function control, including replacement of technical spare parts, system function for several years is assured.

\section{Classification of the MCSS}

The MCSS can be categorized according to the type of pump: (I) pulsatile: volume displacement pump and (II) non-pulsatile: axial or centrifugal rotary pumps with continuous flow.

In the 1980s, pulsatile pneumatic extracorporeal systems followed by first generation electromechanical pulsatile implantable VADs have been initially used. Presently, the second and third generation non-pulsatile implantable systems dominate the market (Table 2).

The beginners' flaws of the new technology were quickly overcome; new concepts and further miniaturization with improved reliability and biocompatibility then prevailed. Rotary blood pumps (RBPs) were soon preferred and clinical success stimulated manufacturers to come up with newer concepts. A comparison of the systems is shown in Table 2.

Pulsatile extracorporeal systems and the temporary TAH are almost unrivaled in children and in those requiring a BVAD support.

The successful first application in Berlin have shown that certain RBPs with continuous flow can also be implanted as BVADs (43). Continuous flow pumps (centrifugal or axial) are currently used for adults and large children. Their advantage over pulsatile systems is the long durability, small size, silence and the low energy consumption.

\section{Physical principles and concepts of pumps}

Blood pumps can work according to different hydromechanical principles as pulsatile volume displacement or continuous flow (rotary pumps with axial or radial pumps) (44). The pumps can be positioned outside the body (extracorporeal) or inside the body (intracorporeal, implantable). All systems are dependent on external energy supply connected to the implanted pumps via percutaneous cables. The energy supply through an undamaged skin is fundamentally possible by induction via an external and an implanted coil. However, this is currently not available, as it is still undergoing approval for clinical application.

\section{Pulsatile systems}

Blood pumps with elastic blood chambers are designed as positive displacement pumps, activated by pneumatic, hydraulic or mechanical compression devices usually driven by electric motors. The disadvantage of this concept is that the volume must be equalized with the blood flow volume, 
Table 3 MCSS systems approved in Europe and the USA

\begin{tabular}{lll}
\hline Types of support & Pulsatile & Non-pulsatile \\
\hline Extracorporeal & & \\
Short-term support & None available & TandemHeart PTVA \\
& & CentriMag \\
Long-term support & EXCOR $^{\circledR}$ (implanted in Berlin since 1990) & Abiomed Impella \\
Intracorporeal & & \\
Long-term support & SynCardia (previously CardioWest) temporary Total & HeartAssist 5 (previously MicroMed DeBakey VAD) \\
& Artificial Heart (t-TAH-t) & HeartMate II LVAS \\
& & Jarvik 2000 \\
& & HeartWare HVAD \\
& & HeartMate 3 \\
\hline
\end{tabular}

either through a connection to the free atmosphere (vented system) or to a volume compensation chamber implanted in the body. These pumps can produce a flow similar to natural blood flow, with periods of stoppage (filling, diastole) and ejection (emptying, systole). Pulsatile pumps require valves similar to the heart valves in order to generate a directed blood flow.

\section{Non-pulsatile systems-RBPs}

The first RBPs were small axial turbines driven by external electric motors at the catheter tip via long flexible shafts. Today, this system is only of historical significance (45); however, the principle of the intravascular RBP (Impella) has further evolved.

RBPs create a continuous flow and do not require valves, smaller than volume displacement pumps, easier to implant, do not require volume compensation and only have one moving component (rotor) with low mechanical stress. The long-term operational reliability is considerably higher than that of pulsatile pumps. No abrasion occurs if the rotor is supported without contact by magnetic bearings or the combination of hydrodynamic-magnetic bearings, hence, the service time is theoretically unlimited.

The initial concerns about the possible negative effects of a continuous, perfusion on end-organ function have now been resolved through clinical experience of thousands of implantations of such systems with operating times up to several years.

\section{Present systems}

The MCSS approved for clinical use in Europe and the USA in 2019 are summarized in Table 3. Some previous clinically proven systems had been withdrawn from the market by the manufacturers for undisclosed reasons and are not on this list.

The technical construction, fluid dynamic function and material composition of the different electro-pneumatic, electro-mechanical, electromagnetic and electro-hydraulic activated systems are highly complex (46) making a detailed description go beyond the scope of this paper. Further information is found on the website of the manufacturers, hence only the functional principles are summarized.

\section{Extracorporeal non-pulsatile systems for short-term use}

These relatively cheap and easy-to-connect systems are used when one or both ventricles fail acutely and a prospect of recovery with ventricular unloading exists. If no improvement occurs, the systems can be replaced with a longer-term system. Extracorporeal systems are the choice for biventricular HF, i.e., Tandem Heart pVAD (CardiacAssist Inc., Pittsburgh, PA, USA), Levitronix CentriMag (Levitronix LLC; Waltham, MA, USA) (47) and Impella (Abiomed, Danvers, MA, USA).

\section{Extracorporeal membrane oxygenation}

ECMO takes over or supports either the systemic or pulmonary circulation, for a shorter (up to 5 days) or longer 
period (up to 25-30 days) depending on the clinical picture. ECMO is generally continued until the underlying cardiac or pulmonary condition is improved or resolved. Longterm ECMO support increases the risks of complications. Discontinuance of ECMO support is determined after careful assessment of cardiopulmonary status and the patient's ability to resume near-normal function with minimal support and intervention.

In general, the aim is to implant ECMO in a patient with a cardiac index of $<2.0 \mathrm{~L} / \mathrm{min} / \mathrm{m}^{2}$, with a highdose catecholamine administration and/or with an intraaortic balloon pump (IABP) inserted in critical STEMI. The implantation of an IABP in STEMI patients, if the cardiogenic shock cannot be quickly eliminated with medication, is now a recommendation of class I. Indications of ECMO support in cardiogenic shock are unsuccessful weaning after extracorporeal circulation, progressive low cardiac output syndromes, acute graft rejection or graft failure after heart or lung transplantation, acute myocardial infarction, extracorporeal cardiopulmonary resuscitation, intractable arrhythmia, cardiomyopathies and myocarditis, sepsis and high-risk interventional coronary (PTCA) or valve (TAVI) procedures. The primary goal is avoidance of end organ damage from reduced perfusion and hypoxemia. It is used in a stepwise concept, e.g., as a bridge-to-bridge strategy, which may be followed by implantation of LVAD, right VAD (RVAD) or BVAD. Basically, myocardial recovery is possible, and particularly promising in myocarditis (48).

\section{Extracorporeal pulsatile MCSS for long-term use}

EXCOR $^{\circledR}$ (Berlin Heart GmbH, Berlin, Germany) is a pneumatic extracorporeal system implanted either as univentricular or biventricular support. It offers a large selection of pumps with stroke volumes from 10 to $80 \mathrm{~mL}$, with a variety of shape and sizes of the apical, atrial and arterial cannulas as well as stationary and small mobile electropneumatic drives, which are a unique adaptation option from newborns to toddlers to adults. It comes with a stationary IKUS driver used for large $(50-80 \mathrm{~mL}$ stroke volume) and smaller (10-30 mL stroke volume) blood pumps. Since November 2019, a new mobile EXCOR Active System designed for small children has been launched (49).

\section{Implantable pulsatile MCSS for long-term use}

Long-term implantable MCSS are designed for BTR and for BTT. In exceptional cases, they are also chosen for permanent support (destination therapy). The manufacturers have removed several of these systems from the market.

\section{Implantable pulsatile TAH for temporary or long-term use}

The special implantable systems used clinically today are the TAHs, i.e., two artificial ventricles for the orthotopic replacement of the heart. As with OHT, the natural heart is removed, then two separate pumps or a two-chamber mechanical blood pump is connected to the atria (left and right atrium) and large vessels (aorta, pulmonary artery).

SynCardia (formerly CardioWest) temporary total artificial heart (TAH-t) (SynCardia Systems, Inc.) is a pneumatically driven TAH, a further development of the JARVIK-7 TAH, first used clinically in 1982. This is the only one available worldwide for temporary implantation as a BTT, approved by the FDA and CE certified. Unfortunately, the pumps are bulky and are implantable only in relatively tall patients. The device is currently available with a stroke volume of $70 \mathrm{~mL}$ as well as in a smaller version.

CARMAT TAH, the newest TAH, offers a long-term support to patients with end-stage HF in the face of donor organ shortage. What differentiates CARMAT TAH from existing artificial hearts and VADs is its biocompatibility, pulsatility and autoregulation i.e., immediate, automated response to the physiological needs of the patient (50).

The challenge in this TAH system is the long-term durability of the membranes and valves.

Yuriy Pya, from Astana, Kazakhstan, implanted CARMAT TAH on 3 patients as a BTT. The first was on October 19, 2017, and this patient was supported for 243 days, the longest period of TAH support. The second was implanted on March 2, 2018 and supported for 155 days. The third was supported for 109 days from June 13, 2018 (personal information from Dr. Pya). So far, 5 such implantations were performed by Ivan Netuka in Prague.

\section{Long-term implantable support systems with axial flow}

Clinically available axial pumps from different manufacturers have similar system configurations. The pump is implanted in the chest; the electronic control unit, the energy supply for stationary and mobile operation, a battery charger and a setting monitor for the operating 
parameters (speed, alarm limits) and function remain outside the body. A percutaneous flexible cable connects the pump to the mobile external component, fixed in the tissue which protects the wound from infections.

HeartAssist 5 LVAD (MicroMed Cardiovascular Inc., Houston, TX, USA) formerly MicroMed DeBakey VAD, is small and compact, weighing $92 \mathrm{~g}$ and can easily be implanted above the diaphragm (51). This is the only rotary LVAD wherein the flow is measured directly at the outflow prosthesis with an ultrasonic transducer, enabling a reliable system monitoring.

HeartMate II LVAS (Abbott Laboratories, Pleasanton, CA, USA) has a similar structure, but with a different $\mathrm{LV}$ apical cannulation technique. In contrast to the rigid, curved inlet cannula of the MicroMed, the HM II apex connector is flexibly connected to the pump inlet via a vascular prosthesis. This has proven advantageous for pump positioning and integrating the connector into the myocardium. The system is slightly larger than the HeartAssist 5, hence a pocket for the pump is prepared under the abdominal wall during implantation.

Jarvik 2000 (Jarvik Heart, Inc., New York, NY, USA) differs significantly from the previously described systems in terms of positioning, technical structure, electronic concept as well as performance (52). The pump is implanted directly into the $\mathrm{LV}$ apex through a left lateral thoracotomy and fixed with a suture cuff. A special feature is the skin tunneling for the drive cable. A titanium socket, proven as an infection-free energy transfer for cochlear implants, is screwed to the top of the skull retro-auricularly and connected to the percutaneously placed drive cable. Even with minimal care, the skin remains infection-free (53).

This pump is made in two smaller versions for use in small children. No information is available regarding implantations. Further trials were rejected by the US FDA.

\section{Long-term implantable support systems with radial flow}

HeartWare HVAD system (Medtronic Inc., MN, USA) is the world's smallest, commercially available, full-support centrifugal VAD designed to be implanted completely within the pericardial space (54). A combined passive magnetic and hydrodynamic bearing without complex electronics increases the functional reliability requiring the highest manufacturing precision.

HeartMate 3 (Abbott Laboratories, Pleasanton, CA, USA) has won FDA approval to be used as a destination therapy for advanced HF patients who are not eligible for a transplant. Previously, the device has been indicated for patients eligible and waiting for a transplantation. It is the first system with essential parts of the control electronics integrated in the pump and despite the active magnetic bearing, the supply line is simple, flexible and safe (55).

\section{Partial flow systems-systems for partial heart support}

Partial flow systems can only replace part of the heart's pumping activity. They are intended to close a supply gap for patients who can no longer be adequately treated with medication, but who are not yet in end stage HF. The improvement in circulatory function is expected to prevent a progression of HF or even a recovery of cardiac activity. However, the Circulite and Synergy systems have been removed from the market.

\section{MCS for infants and children}

The initially clinically available MCSSs were designed according to the performance and anatomical adaptation to the needs of adults. However, it soon became necessary to develop MCS systems suitable for small patients (body weight 3 to $30 \mathrm{~kg}$ ) with a small cardiac output.

$\mathrm{EXCOR}^{\circledR}$, an extracorporeal pneumatic system, was used as the first pediatric system as a BTT with a $50 \mathrm{~mL}$ pump in 1990 in Berlin (36). An infant system with a $10 \mathrm{~mL}$ pump was first implanted in 1992 (56). A variation of pumps (10, $15,25,30,50 \mathrm{~mL}$ ) with corresponding sizes of the cannulas are presently available. The system is approved since 2014 for clinical use in the United States.

In 2006, the PumpKIN Trial, funded by the National Heart, Lung, and Blood Institute for patients with a body weight of $2-25 \mathrm{~kg}$ began with 5 projects. None of these systems reached clinical maturity. Meanwhile, only the scaled-down Jarvik 2000 version is under discussion but unavailable. A new variant was scheduled to be tested in 2019. $\mathrm{EXCOR}^{\circledR}$ is the only one available worldwide, at least for small children and infants.

The smaller HeartWare and HeartMate3 centrifugal pumps can be used for older and bigger children.

\section{Complications}

It is important to remember that such devices are only implanted to keep patients alive or in immediate life- 
threatening stages. This poses arguments to attribute complications to the pumps or to the advanced states of the disease.

\section{System malfunctions}

The blood pumps, the most important part of the VAD, are subject to special requirements with regard to fatigue resistance and reliability (57).

In the pneumatically operated systems, the membranes or blood chambers, subject to high mechanical stress associated with bending and stretching of the material, may rupture resulting in blood leakage into the air chamber or air embolism in the blood chamber; however, the risk is very low (58).

Occasional malfunction of the mechanical valves occur from breaks in the flap disc or the holding bracket and a jamming/squeezing of the valve in the valve ring.

Thrombus formation in the blood chambers is more frequently observed, either through insufficient or inadequate anticoagulation therapy, infections, or poor flow through the pump (hypovolemia) necessitating a pump replacement.

In addition to the complications arising from infections at the skin exit points and depending on the position of the pumps, the cannulas can bend when the patient moves. If this kinking occurs frequently and always in the same places on the cannulas, crack formation occurs and risk of bleeding or air embolism increases.

In implantable systems, the electrical supply lines to the pumps are the mechanically most stressed components. There could be breaks in the live wires with corresponding malfunctions or pump failure. Cable defects were repeatedly observed in various models making pump replacement necessary.

Even with permanent, easy-to-use systems with a sophisticated alarm system, fatal incidents occur due to incorrect patient handling. VADs are increasingly being used in elderly patients who, sometimes during the therapy, suffer from cognitive or manual restrictions, unable to cope with previous extensive and repeated training in system operation.

\section{Hemolysis}

There is always a risk of damage to the blood components using mechanical pumps. Damage is caused by blood contact with the foreign surfaces and stresses on the blood cells due to the shearing forces generated during pump activity which are size- and pressure-dependent.

Unlike in the pioneering days, hemolysis is generally of no importance in the pumps currently available. This is demonstrated by the fact that it makes no significant difference whether the patient is equipped with one or two well-functioning pumps. However, hemolysis may occur due to other causes, i.e., infections or medications.

\section{Thromboembolism}

Even with carefully monitored anticoagulation according to the different requirements of individual systems, clots can form when the blood comes into contact with the biomaterials (titanium, silicone, polyurethane, etc.). This complication is facilitated by unfavorable flow conditions in areas with stagnant flow and poor washout performance.

\section{Bleeding}

There is always a risk of surgical bleeding in the perioperative phase post-MCSS implantation. The bleeding tendency is promoted by the profound shock, which induces coagulation disorders in itself, and from excessive anticoagulation, trauma and infections. Gastrointestinal bleeding is often observed. There appears to be a correlation between the pulsatility of the blood flow and the bleeding frequency $(59,60)$.

Cerebral hemorrhages are particularly critical occurring with excessive anticoagulation as well as with cerebral thromboembolism with subsequent vascular necrosis. Anticoagulation therapy poses difficulties because on one hand, normalized coagulation is required to prevent further bleeding, and on the other hand, pump thrombosis must be prevented. Both scenarios are immediately life-threatening.

It has been observed that RBPs are more commonly associated with a deficiency or destruction of the von Willebrand factor and a subsequent cerebral bleeding tendency (61-63). In our experience, this occurred early after VAD implantation in elderly patients.

\section{Infection}

Early onset of infections post-VAD/TAH implantations occur in 5-20\%; with long-term use, the rate rises to $90 \%$ depending on the system. Circulatory failure and comorbidities are contributory risk factors for infections.

The skin exit points are constantly mildly inflamed and 
can be infected despite careful wound care. Thus, it forms an entry gate of bacteria into the body with infections possibly reaching the implant.

It is particularly serious when infection spreads to the inlet cannula at the top of the left chamber. This can result in the cannula migrating out of the chamber and the formation of a myocardial aneurysm, with a risk of rupture and recurrence even after surgical treatment.

Years ago, inductive "transcutaneous energy transmission systems" (TETS) were developed for the supply of energy and the transmission of data and control signals through the undamaged body surface. The energy transmission system of the Jarvik 2000 pump with its titanium plug screwed behind the ear on the skull cap with the subcutaneous cable routing is an attractive solution. Almost no infections were observed in this configuration.

\section{Anastomotic problems}

Wound healing disorders at the apical cannulations are common, but not often described. This problem was investigated in Berlin patients with eleven different longterm systems in more than 200 autopsies. Even without infection, it is not uncommon for granulation tissue to form in the chamber around the cannula, which maybe extensive enough to move the cannula or even embolize into the pump, commonly in pumps with a rigid connection to the inlet cannula.

A microporous surface structure allows the myocardial cells to form a fixed neointima. In smooth metallic surfaces, thrombotic growths initially form, subsequently becoming a granulation tissue. Aneurysmal formation in aortic anastomoses likewise could develop.

\section{Aortic valve insufficiency}

Aortic valve insufficiency is a significant threat to the LVAD function and develop consecutively over time in a rotary pump. Recirculation through the incompetent aortic valve is more severe in continuous flow systems than in pulsatile pumps. Despite the increasing flow through the LVAD, blood flow to the end organs decreases and signs of HF increase $(64,65)$. All forms of aortic valve insufficiency must be addressed, either primarily when LVAD is implanted or later when it is progressive. This can be done surgically by valve reconstruction, closure or replacement or through a catheter procedure $(66,67)$.

\section{Right HF}

Impairment of right heart function immediately after implantation occurs in $25-35 \%$ of LVAD patients $(68,69)$. In Berlin, the rate reported is 15\% (70).

Inadequate right heart function influences the left heart performance. When this becomes refractory to maximal drug therapies, temporary extracorporeal right heart support is indicated. In the presence of a pulmonary gas exchange disturbance, the RVAD can be combined with an oxygenator. Implantation of a long-term RVAD is the ultimate resort if the right heart insufficiency or right HF persists.

\section{Anatomically related flow restrictions}

Tight anatomical conditions in the chest (in small patients or with very voluminous blood pumps) can compress the venous system and other blood vessels or hinder the appropriate placement of the apical cannula. This may even result in a complete standstill of pump function. Intraoperative transesophageal echocardiography can identify incorrect positions and allow correction.

\section{Arrhythmias}

Many patients on MCSS support already possess a cardioverter/defibrillator (ICD) before the implantation.

With ventricular arrhythmias - tachycardia or fibrillation, the delivery capacity of the left pump decreases due to reduced or inadequate right heart performance, especially in those with pulmonary hypertension. The apical cannula may be sucked up leading to a total pump failure. Only an ICD can normalize the situation.

Patients with BVAD with good inflow conditions are not affected by such severe rhythm disorders. Some of our patients have survived fibrillation for longer periods without symptoms.

\section{Technical follow-up}

Patients who are discharged home are technically supervised and monitored and advised to come to the clinic for outpatient follow-up at intervals of several months. A 24-hour/7-day hotline is primarily available to deal with acute problems.

We have instituted remote monitoring of the system function, similar to telemedicine devices, wherein data can 
be called up and analyzed in a dialogue with the patient using the wireless telephone networks and the Internet. An internal system data recording is a prerequisite. It enables the diagnosis and, if necessary, the reconstruction of the chronological sequence of alarms.

\section{Summary and outlook}

Long-term MCSS have been in clinical application since the 1980s and were initially used to bridge a lifethreatening condition for a limited time until a subsequent heart transplant becomes foreseeable. Over time, longterm systems evolved, and some patients inevitably had to use these pumps throughout their lives if they could not be transplanted.

Technical improvements and increased implantation of TAH as a BTT do not fundamentally help solve the donor problem, However, these systems have improved the care and life expectancy of patients, traditionally reserved for a heart transplantation. In Germany, the number of organ donors is steadily declining. The number of patients on the waiting list rises, thereby use of bridging systems increases; hence, the likelihood of an individual being transplanted decreases. Nevertheless, the concept of bridging until an eventual heart transplantation established the use and acceptance of MCSS.

A future solution is the provision of long-term implantable, secure technical systems with the least possible reduction in the quality of life, enabling a significant extension of life. Then MCSS can be firmly viewed as a transplant alternative.

It seems certain that the future of MCSS belongs to the RBPs. The systems are noiseless, will be further reduced in size, will be more less invasively implantable. New fluid dynamic designs and optimized blood contact surfaces will further improve biocompatibility. Necessary medical therapies, i.e., coagulation management, may then be reduced or completely eliminated.

The size reduction of the tried-and-tested temporary TAH CardioWest will potentiate its implantation in smaller patients.

Acknowledging the need for long-term implantable biventricular MCSS or heart replacement, research groups worldwide have been trying for decades to develop suitable TAH systems with modern concepts and with immense financial expenditures supported by state funds with industrial collaboration without further clinical success.
The French CARMAT project has had initial success in Kazakhstan and Prague. We will see then its further development.

As an alternative to the voluminous artificial heart systems based on displacement pumps, efforts are being made to implement systems with potential to replace the whole heart by combining two RBPs based on the existing permanent LVAD systems and clinical experience with thousands of patients (71).

RBPs of the second or third generation either with noncontact magnetic or magnetic-hydrodynamic bearings and high fatigue strength have proven their long-term suitability with an acceptable complication rate. With the Friede Springer Heart Foundation support, investigations into the suitability of clinically approved LVADs for biventricular heart support or heart replacement (TAHROT) were started in 2009 in Berlin (43). Such rotary pumps were eventually implanted as BVAD in patients with terminal biventricular HF (38). The working area of the pump acting as RVAD, originally conceived as LVAD, is transformed into a flow pressure area of the circulation by constricting the pulmonary outflow without changing the pump design.

The development of even smaller rotary LVADs and possibly BVADs is encouraging.

The latest VAD, the Heartmate 3, fulfills the desire for fewer complications and good long-term function. The aim is its long-term use without or with minimal anticoagulation.

To improve the quality of life for patients, a transcutaneous energy transmission system (TETS) was developed to supply fully implantable blood pumps. It enables data and energy transfer through the uninjured skin, thereby eliminating the risk of infection on the cable exit wound.

The current state of the art and medical experience allow the use of MCSS for various indications including permanent replacement of cardiac function with reasonable risks and limitations in quality of life.

The aftercare of patients by specially trained technical and medical personnel has become increasingly important to identify and avoid complications and to give the patient the security of living with the system. Telemonitoring of external VAD patients will be helpful.

Now that the MCSS can be used as an alternative to OHT, the number of patients who require outpatient care from the implanting clinics will rapidly increase. Additional personnel must be provided to ensure the follow-up tasks. 


\section{Acknowledgments}

Funding: None.

\section{Footnote}

Provenance and Peer Review: This article was commissioned by the editorial office, Cardiovascular Diagnosis and Therapy for the series "Heart Failure in the Young and Old: Insights into Various Therapies". The article has undergone external peer review.

Conflicts of Interest: All authors have completed the ICMJE uniform disclosure forms (available at http://dx.doi. org/10.21037/cdt-20-283). The series "Heart Failure in the Young and Old: Insights into Various Therapies" was commissioned by the editorial office without any funding or sponsorship. RH served as the unpaid Guest Editor of the series and serves as an unpaid editorial board member of Cardiovascular Diagnosis and Therapy from July 2019 to Jun 2021. The authors have no other conflicts of interest to declare.

Ethical Statement: The authors are accountable for all aspects of the work in ensuring that questions related to the accuracy or integrity of any part of the work are appropriately investigated and resolved.

Open Access Statement: This is an Open Access article distributed in accordance with the Creative Commons Attribution-NonCommercial-NoDerivs 4.0 International License (CC BY-NC-ND 4.0), which permits the noncommercial replication and distribution of the article with the strict proviso that no changes or edits are made and the original work is properly cited (including links to both the formal publication through the relevant DOI and the license). See: https://creativecommons.org/licenses/by-nc-nd/4.0/.

\section{References}

1. Shumacker HB Jr. A surgeon to remember: notes about Vladimir Demikhov. Ann Thorac Surg 1994;58:1196-8.

2. Carrel A, Lindbergh CA. The culture of organs. NewYork: Paul B. Hoeber, Inc., 1938.

3. Dennis C, Spreng DS Jr, Nelson GE, et al. Development of a pump-oxygenator to replace the heart and lungs; an apparatus applicable to human patients, and application to one case. Ann Surg 1951;134:709-21.
4. Dennis C, Karlson KE, Eder WP, et al. Pump-oxygenator to supplant the heart and lungs and brief periods. A method applicable to dogs. Surgery 1951;29:697-713.

5. Miller BJ, Gibbon JH Jr, Greco VF, et al. The production and repair of interatrial septal defects under direct vision with the assistance of an extracorporeal pump-oxygenator circuit. J Thorac Surg 1953;26:598-616; discussion 631-2.

6. Kolff WJ, Effler DB, Groves LK, et al. Disposable membrane oxygenator (heart-lung machine) and its use in experimental surgery. Cleve Clin Q 1956;23:69-97.

7. Akutsu T, Houston CS, Kolff WJ. Artificial hearts inside the chest, using small electro-motors. Trans Am Soc Artif Intern Organs 1960;6:299-304.

8. Akutsu T, Houston NCS, Kolff WJ. Roller type of artificial heart within the chest: preliminary report. Am Heart J 1960;59:731-6.

9. Akutsu T, Seidel W, Mirkovitch V, et al An electromotordriven pendulum-type artificial heart inside the chest. Trans Am Soc Artif Intern Organs 1961;7:374-7.

10. Moulopoulos SD, Topaz SR, Kolff WJ. Extracorporeal assistance to the circulation and intraaortic balloon pumping. Trans Am Soc Artif Intern Organs 1962;8:85-9.

11. Liotta D, Hall CW, Henly WS, et al. Prolonged assisted circulation during and after cardiac or aortic surgery. Prolonged partial left ventricular bypass by means of intracorporeal circulation. Am J Cardiol 1963;12:399-405.

12. Liotta D, Maness J, Bourland H, et al. Recent modifications in the implantable left ventricular bypass. Trans Am Soc Artif Intern Organs 1965;11:284-90.

13. Cooley DA, Liotta D, Hallman GL, et al. Orthotopic cardiac prosthesis for two staged cardiac replacement. Am J Cardiol 1969;24:723-30.

14. Cooley DA, Akutsu T, Norman JC, et al. Total artificial heart in two-staged cardiac transplantation. Cardiovasc Dis 1981;8:305-19.

15. Pennington DG, McBride LR, Swartz MT, et al. Left atrial-aortic (LA-Ao) perfusion with a ventricular assist device (VAD). Trans Am Soc Artif Intern Organs 1982;28:579-83.

16. Jorge E, Pae WE Jr, Pierce WS. Left heart and biventricular bypass. Crit Care Clin 1986;2:267-75.

17. Shiono M, Takatani S, Sasaki T, et al. Baylor multipurpose circulatory support system for short- to long-term use. ASAIO J 1992;38:M301-5.

18. Petrovskiĭ BV, Shumakov VI. Artificial heart implanted into the organism. Kardiologiia 1967;7:14-20.

19. Shumakov VI. Artificial heart implanted in the thoracic cavity. Kardiologiia 1967;7:112-20. 
20. Wolner E, Deutsch M, Losert U, et al. Clinical application of the ellipsoid left heart assist device. Artif Organs Aug 1978;2:268-72.

21. Bücherl ES. The artificial heart. Verh Dtsch Ges Inn Med 1981;87:1538-49.

22. Schmitz KP, Nabel HJ, Scharf W, et al. Noninvasive monitoring of pneumatically driven blood pumps based on measurements of air volume flow in the drive hose. $\mathrm{Z}$ Gesamte Inn Med 1987;42:645-9.

23. Joyce LD, DeVries WC, Hastings WL, et al. Response of the human body to the first permanent implant of the Jarvik-7 Total Artificial Heart. Trans Am Soc Artif Intern Organs 1983;29:81-7.

24. DeVries WC, Anderson JL, Joyce LD, et al. Clinical use of the total artificial heart. N Engl J Med 1984;310:273-8.

25. Pavie A, Leger P, Regan M, et al. Clinical experience with a total artificial heart as a bridge for transplantation: the pitie experience. J Card Surg 1995;10:552-8.

26. Ménard J. Keys to the success of the CARMAT project? Med Sci (Paris) 2014;30:204-5.

27. Palenker J, Lüsebrink R, Kaiser M, et al. Temporary implantation of the Berlin artificial heart system. Int J Artif Organs 1987;10:263-8.

28. Hetzer R, Hennig E, Schiessler A, et al. Mechanical circulatory support and heart transplantation. J Heart Lung Transplant 1992;11:S175-81.

29. Moritz A, Wolner E, Nose Y. Clinical use of the artificial heart, indications and results. Wien Klin Wochenschr 1988;100:161-7.

30. Shumakov VI, Zimin NK. Implantation of the artificial heart. Med Tekh 1987;(5):8-13.

31. Norman JC, Brook MI, Cooley DA, et al. Total support of the circulation of a patient with post-cardiotomy stoneheart syndrome by a partial artificial heart (ALVAD) for 5 days followed by heart and kidney transplantation. Lancet 1978;1:1125-7.

32. Bernhard WF, Berger RL, Stetz JP, et al. Temporary left ventricular bypass: factors affecting patient survival. Circulation 1979;60:131-41.

33. Pae WE Jr, Rosenberg G, Pierce WS. Experimental and clinical experience with the Pennsylvania State University total artificial heart. Life Support Syst 1987;5:259-65.

34. Turina M, Bosio R, Senning A. Clinical application of paracorporeal uni- and biventricular artificial heart. Trans Am Soc Artif Intern Organs 1978;24:625-31.

35. Hennig E, Zartnack F, Schiessler A, et al. The Berlin Heart assist system. Biomed Tech (Berl) 1990;35 Suppl 3:294-6.
36. Warnecke H, Berdjis F, Hennig E, et al. Mechanical left ventricular support as a bridge to cardiac transplantation in childhood. Eur J Cardiothorac Surg 1991;5:330-3.

37. Noon GP, Morley D, Irwin S, et al. Development and clinical application of the MicroMed DeBakey VAD. Curr Opin Cardiol 2000;15:166-71.

38. Hetzer R, Kaufmann F, Potapov E, et al. Rotary blood pumps as long-term mechanical circulatory support: A review of a 15 -year Berlin experience. Semin Thorac Cardiovasc Surg. Spring 2016;28:12-23.

39. Deutscher Herzbericht 2018. Sektorenübergreifende Versorgungsanalyse zur Kardiologie, Herzchirurgie und Kinderherzmedizin in Deutschland. Deutsche Herzstiftung e.V. Frankfurt am Main 2018:19-50.

40. Stevenson LW, Pagani FD, Young JB, et al. INTERMACS profiles of advanced heart failure: the current picture. J Heart Lung Transplant 2009;28:535-41.

41. Hetzer R, Kaufmann F, Delmo Walter EM. In: Kramme R. editor. Medizintechnik. Verfahren-SystemeInformationsverarbeitung, 5. Aufl. Berlin: Springer, 2015:S557.

42. Griepp RB, Stinson EB, Dong E, et al. Acute rejection of the allografted human heart: diagnosis and treatment. Ann Thorac Surg 1971;12:113-26.

43. Hetzer R, Krabatsch T, Stepanenko A, et al. Long-term biventricular support with the HeartWare implantable continuous flow pump. J Heart Lung Transplant 2010;29:822-4.

44. Trummer G. VAD-Systeme (Ventricular Assist Devices). In: Kramme R. editor. Medizintechnik. VerfahrenSysteme-Informationsverarbeitung, 3. Aufl. Berlin: Springer, 2007:569-78.

45. Wampler RK, Moise JC, Frazier OH, et al. In vivo evaluation of a peripheral vascular access axial flow blood pump. ASAIO Trans 1988;34:450-4.

46. Gemmato CJ, Forrester MD, Myers TJ, et al. Thirtyfive years of mechanical circulatory support at the Texas Heart Institute: an updated overview. Tex Heart Inst J 2005;32:168-77.

47. Centrimag acute circulatory support system. 2020. [Accessed on 20th April 2020]. Available online: https:// www.cardiovascular.abbott/us/en/hcp/products/heartfailure/centrimag-acute-circulatory-support-system.html

48. Extracorporeal Life support Organization. ELSO Adult Cardiac Failure Supplement to the ELSO General Guidelines Version 1.3 December 2013. [Accessed on 20th April 2020]. Available online: https://www.elso.org/ Resources/Guidelines.aspx 
49. EXCOR® PEDIATRIC. Berlin: EXCOR Active 2020. [Accessed on 20. April 2020]. Available online: https:// www.berlinheart.de/medical-professionals/excorr-active/

50. The Carmat prosthesis. 2017. [Accessed on 20th April 2020]. Available online: https://www.carmatsa.com

51. A Milestone for MicroMed Cardiovascular. 2012. [Accessed on 20th April 2020]. Available online: https://www. biospace.com/article/releases/a-milestone-for-micromedcardiovascular-/

52. The Jarvik 2000®. 2020. [Accessed on 20th April 2020]. Available online: https://www.jarvikheart.com/products/ the-jarvik-2000/

53. Siegenthaler MP, Frazier OH, Beyersdorf F, et al. Mechanical reliability of the Jarvik 2000 Heart. Ann Thorac Surg 2006;81:1752-8; discussion 1758-9.

54. HeartWare HVAD System. 2020. [Last Updated February 2020; Accessed on 20th April 2020]. Available online: https://www.medtronic.com/us-en/healthcareprofessionals/products/cardiac-rhythm/ventricular-assistdevices/heartware-hvad-system.html

55. HeartMate 3TM LVAD. 2020. [Accessed on 20th April 2020]. Available online: https://www.heartmate.com/ healthcare-provider/heartmate-3-lvad

56. Hetzer R, Loebe M, Potapov EV, et al. Circulatory support with pneumatic paracorporeal ventricular assist device in infants and children. Ann Thorac Surg 1998;66:1498-506.

57. Birks EJ, Tansley PD, Yacoub MH, et al. Incidence and clinical management of lift-threatening left ventricular assist device failure. J Heart Lung Transplant 2004;23:964-9.

58. Martin J, Friesewinkel O, Benk C, et al. Improved durability of the HeartMate XVE left ventricular assist device provides safe mechanical support up to 1 year but is associated with high risk of device failure in the second year. J Heart Lung Transplant 2006;25:384-90.

59. Crow S. John R, Boyle A et al. Gastrointestinal bleeding rates in recipients of continuous flow and pulsatile left ventricular assist devices. J Thorac Cardiovasc Surg 2009;137:208-15.

60. Slaughter MS, Rogers JG, Milano CA, et al. Advanced heart failure treated with continuous-flow left ventricular assist device. N Engl J Med 2009;361:2241-51.

61. Crow S, Chen D, Milano C, et al. Acquired von Willebrand syndrome in continuous-flow ventricular assist device recipients. Ann Thorac Surg 2010;90:1263-9; discussion 1269.

62. Meyer AL, Malehsa D, Bara C, et al. Acquired von Willebrand syndrome in patients with an axial flow left ventricular assist device. Circ Heart Fail 2010;3:675-81.

63. Uriel N, Pak SW, Jorde UP, et al. Acquired von Willebrand syndrome after continuous-flow mechanical device support contributes to a high prevalence of bleeding during long-term support and at the time of transplantation. J Am Coll Cardiol 2010;56:1207-13.

64. John R, Mantz K, Eckman P, et al. Aortic valve pathophysiology during left ventricular assist device support. J Heart Lung Transplant 2010;29:1321-9.

65. Jorde UP, Uriel N, Nahumi N, et al. Prevalence, significance, and management of aortic insufficiency in continuous flow left ventricular assist device recipients. Circ Heart Fail 2014;7:310-9.

66. Dranishnikov N, Stepanenko S, Potapov EV, et al. Simultaneous aortic valve replacement in left ventricular assist device recipients: single center experience. Int J Artif Organs 2012;35:489-94.

67. D'Ancona G, Pasic M, Buz S, et al. TAVI for pure aortic valve insufficiency in a patient with a left ventricular assist device. Ann Thorac Surg 2012;93:e89-91.

68. Dandel M, Hetzer R. Evaluation of the right ventricle by echocardiography: particularities and major challenges. Expert Reviews of Cardiovascular Therapy 2018;16:259-75.

69. Dandel M, Hetzer R. Temporary assist device support for the right ventricle: pre-implant and post-implant challenges. Heart Failure Reviews 2018;23:157-71.

70. Potapov EV, Loforte A, Weng Y, et al. Experience with over 1000 implanted ventricular assist devices. J Card Surg 2008;23:185-94.

71. Frazier OH, Tuzun E, Cohn WE, et al. Total heart replacement using dual intracorporeal continuous-flow pumps in a chronic bovine model: a feasibility study. ASAIO J 2006;52:145-9.
Cite this article as: Hetzer R, Javier MFDM, Dandel M, Loebe M, Javier Delmo EM. Mechanical circulatory support systems: evolution, the systems and outlook. Cardiovasc Diagn Ther 2021;11(1):309-322. doi: 10.21037/cdt-20-283 